\title{
ABORDAGENS AOS SONS DA CIDADE: ENTRE O COTIDIANO E A PRÁTICA CIENTÍFICA ${ }^{1}$
}

\author{
Renata Silva Machado
}

\section{Introdução}

Tanto na experiência banal quanto na científica, o conteúdo da noção cidade é parcialmente acessado e adquirido através da vivência de componentes sensíveis ${ }^{3}$. Através da audição, da gustação, do tato, da visão, da olfação e de sinestesias destes recursos sensitivos partes da cidade são experienciadas, fruídas. Nesta perspectiva é situado o mote do presente artigo, de tencionar os sons como possível entrada analítica para o estudo da cidade.

Sons da cidade podem ser considerados tema incomum dentre os estudos produzidos nas diferentes áreas que tem a cidade como objeto do conhecimento. Sendo que, nos poucos estudos localizados ${ }^{4}$, identifica-se tendência em por em destaque os efeitos disturbantes dos sons da cidade sobre o espaço e os indivíduos. Poluição sonora, ruído do tráfego, são exemplos da abordagem aos sons da cidade como problema social.

Sugerindo que através da escuta dos sons de um lugar seja possível o movimento de dizer sobre este espaço, e relembrando a pouca utilização dos sons nos estudos sobre a cidade, é proposto estranhamento do lugar dos sons na prática científica. E, neste sentido, questiona-se: por que os sons da cidade são notadamente pouco explorados - como dados de pesquisa e objetos do conhecimento nos estudos em Planejamento Urbano e Regional? Uma vez que sons também constituem, de forma mais específica, a apreensão dos espaços e, de maneira mais generalizada, a experiência humana e a própria cidade.

Portanto, partindo do entendimento dos sons como elementos constitutivos da experiência cotidiana na cidade, e tendo em vista que quando estudados os sons da

\footnotetext{
1 Este trabalho apresenta resultados parciais da pesquisa "Sons da cidade na área Planejamento Urbano e Regional" vinculada a realização de Mestrado Acadêmico em Planejamento Urbano e Regional (PROPUR/UFRGS), desenvolvida sob orientação do Prof. Dr. Eber Pires Marzulo.

2 Universidade Federal do Rio Grande do Sul, Brasil.

${ }^{3}$ Sensíveis no sentido de serem realizadas através dos sentidos da audição, da gustação, do tato, da visão, da olfato.

${ }^{4}$ Foi realizada breve pesquisa exploratória buscando verificar a recorrência do tema sons da cidade na literatura acadêmica brasileira de áreas do conhecimento voltadas ao estudo das questões urbanas.
} 
cidade costumam ser focalizados desde seus efeitos negativos, o presente artigo busca destacar os sentidos como fontes de conteúdo à experiência cotidiana na e da cidade. Destacando a atuação dos sons enquanto experiência sensível constitutiva dos processos de subjetivação na cidade.

Para tanto, serão tratados neste texto respectivamente os sons da cidade, seguido de reflexão sobre a escuta e a percepção dos sons, e sobre a área planejamento urbano e regional no Brasil, sendo apontados alguns tópicos referentes ao estudo dos sons - e de certa forma das experiências sensíveis - nas suas transposições da vida cotidiana para a prática científica.

\section{Sons da Cidade}

Os sons da cidade assim o são nomeados não somente por serem produzidos e projetados neste lugar, mas também por serem escutados, percebidos, significados neste espaço. Na literatura acadêmica os sons da cidade são tratados sob diferentes nomenclaturas ${ }^{5}$ sendo referidos como: paisagens sonoras, ruídos, sons e música.

São relacionais os sentidos atribuídos pelas pessoas aos sons da cidade. Segundo Martin (1995), o ambiente acústico é integrado por uma sucessão constante de sons literalmente sem sentidos. Isto não implica em incompatibilidade entre sons e sentidos, o que ocorre é que são as pessoas que conferem sentidos aos sons. Seja atribuindo-lhes características emotivas - sons de felicidade... sons melancólicos -, seja vinculando-os à locais - som da praia -, atividades - sons do trabalho -, ou ainda atribuindo-lhes valores - barulho do trânsito. Na vida cotidiana ao experienciar sensivelmente os sons da cidade os indivíduos atribuem sentidos a estes, e assim, os sons que percebem passam a integrar e atuar na significação das suas trajetórias. Propõe-se pensar a escuta dos sons da cidade e a atribuição de sentido a estes sons como práticas cotidianas que, como o conjunto destas, constituem fazeres sociais. Pois mesmo ações mais individuais dialogam (não necessariamente no sentido de aderir) se não com conhecimentos prévios ao menos com a contextualização espaçotemporal das mesmas.

Segundo Wisnik, a noção som e sentidos atribuídos a esta noção são construídos no escopo da cultura.

Enquanto experiência do mundo em seu caráter intrinsecamente

\footnotetext{
${ }^{5}$ Conforme apresentado no item 2 deste projeto onde podem ser encontradas referências aos autores de cada enfoque aos sons.
} 
ondulatório, o som projeta o limiar do sentido na medida da sua estabilidade e instabilidade relativas. Este sentido é vazado de historicidade - não há nenhuma medida absoluta para o grau de estabilidade e instabilidade do som, que é sempre produção e interpretação de culturas. (2006: 30).

A partir das reflexões de Wisnik e Martin é reiterada a inexistência de uma associação lógica ou natural entre o som e o sentido. Pois, para ambos, a instauração de sentidos referentes aos sons não pode se dar se não em relação ao seu contexto.

Toma-se como exemplo da inexistência de sentido intrínseco ao som o caso dos sons de carro que em uma corrida de Fórmula 1 podem ser escutados como prazerosos, mas que no caso do tráfego urbano podem ser escutados como incomodo. Ainda nesta direção, a escuta do canto de um mesmo pássaro pode tanto conduzir à plenitude do contato com a natureza no ambiente urbano quanto à plena irritação quando se quer dormir ou estudar. Destes dois exemplos sublinha-se que, primeiro, as fontes sonoras na cidade são múltiplas, segundo, que os limites físicos que separam o privado do público - como as paredes de uma casa - não são barreiras para os sons da mesma forma como o são para a visão do que se passa no interior/exterior das paredes ${ }^{6}$.

As idéias expostas até este ponto conduzem à delimitação da experiência humana marcada pela ininterrupta companhia dos sons. O deslocamento das pessoas no ambiente urbano é exemplo de fonte de produção de sons: passos em uma calçada, alarmes e motores e buzinas e freiadas de carros, músicas cantadas e escutadas em auto-falantes ou fones de ouvido, rangido do metrô nos trilhos, aviões, pingos da chuva, pássaros, vento, ondas do mar, cooler do computador, telefones, falas, respirações...

Além da presença constante de múltiplos sons na cidade, sublinha-se o papel destes na apreensão do espaço. Em outras palavras, o que está sendo proposto é que através da escuta dos sons de um determinado lugar é possível a construção de um dimensionamento do espaço em questão, assim como é possível através do olhar especular sobre a dimensão e as características de um certo espaço. E este dimensionamento pode ser pensado tanto na dimensão da prática cotidiana - ou seja, como ação corriqueira na vida das pessoas na cidade, quanto como procedimento para conhecer cientificamente certo espaço e práticas efetivadas neste.

\footnotetext{
${ }^{6}$ Este exemplo restringe-se as paredes de casas e apartamentos que não foram submetidas a tratamento de isolamento acústico.
} 


\section{A Escuta na Cidade}

Segundo Simmel (1967), na modernidade urbana, a conexão entre a vida social e o mundo material sofre grandes transformações, motivadas pelo emprego do dinheiro enquanto elemento nivelador. Da intensidade de estímulos nervosos característica da cidade e do papel desempenhado pelo dinheiro enquanto nivelador emerge a atitude blasé.

A essência da atitude blasé consiste no embotamento do poder de discriminar. Isto não significa que os objetos não sejam percebidos, como é o caso dos débeis mentais, mas antes que o significado e valores diferenciais das coisas, e daí as próprias coisas, são experimentados como destituídos de substância. Elas aparecem à pessoa blasé num tom uniformemente plano e fosco; objeto algum merece preferência sobre o outro. Esse estado de ânimo é o fiel reflexo subjetivo da economia do dinheiro completamente interiorizada. (Simmel, 1967: 18).

A atitude blasé, que tem nas grandes cidades sua localização genuína, ao assentar-se na presença quantitativamente intensa de estímulos nervosos (em oposição à vida na pequena cidade), e ao carregar como essência o "embotamento do poder de discriminar" (Simmel, 1967: 18) constitui-se em noção cara para a compreensão da percepção dos sons oriundos da cidade. Através da consideração da atitude blasé tomada como resposta dos indivíduos à densidade de possibilidades relacionais no ambiente urbano aliada a características singulares da escuta procura-se ressaltar a dimensão sonora enquanto constituinte inseparável e significativa da vida na cidade.

Quanto às singularidades da escuta como maneira de vivenciar, construir e significar realidades, e, acerca da especificidade do sentido da audição, Schafer salienta que:

O sentido da audição não pode ser desligado a vontade. Não existem pálpebras auditivas.(...) A única proteção para os ouvidos é um elaborado mecanismo psicológico que filtra os sons indesejáveis. (2001: 29).

Propõe-se então, falar da escuta como um sentido receptor de uma grande densidade de estímulos, aos quais muitas vezes as pessoas mostram-se indiferentes. Isto se evidencia, nos casos em que mesmo em ambientes sujeitos a toda sorte de ruídos, num bar, por exemplo, as pessoas utilizem suas capacidades de focarem-se em apenas alguns destes, como na situação de uma conversa. A focalização necessária para a escuta de apenas algumas sonoridades constituidoras de determinada situação social implica na discriminação de outros tantos sons. 
Ao considerar sonoridades como integrantes do dia-a-dia, e, a audição enquanto possibilidade de efetivar a experiência urbana é possível conceber a escuta como prática cotidiana (Certeau, 1994). Desta maneira, as pálpebras auditivas psicológicas pensadas por Schafer (2001) caracterizam-se como atitude blasé performatizada através prática cotidiana da escuta. Ou seja, estas possibilitam que as pessoas ajam de maneira seletiva frente aos muitos estímulos sonoros que produzem e aos quais estão expostas.

\section{Planejamento Urbano e Regional}

Conforme apresentado anteriormente, o presente trabalho busca refletir sobre a relação entre a experiência sensível da cidade e a atuação das aprendizagens banais na prática cientifica. Especialmente quando o fazer cientifico propõe-se à utilização de maneiras sensíveis de apreender o objeto do conhecimento. O questionamento de como tal relação é observada dentre os estudos sobre os sons da área Planejamento Urbano e Regional resulta da minha aproximação recente ${ }^{7}$ aos estudos em planejamento urbano e regional. A partir desta aproximação outras inquietações surgiram. Que é no Brasil a área do conhecimento Planejamento Urbano e Regional (PUR)? E Urbanismo?

No contexto brasileiro coexistem diversos entendimentos sobre a delimitação tanto da área PUR quanto do Urbanismo. As fronteiras entre estas duas áreas do conhecimento parecem estar em constante disputa, sendo delineadas, sobrepostas, borradas, e reescritas, sucessivamente.

Toma-se como ponto de partida para discorrer acerca dos questionamentos colocados anteriormente o momento de consolidação de um campo científico específico para pensar o espaço urbano. Trata-se do processo de consolidação do urbanismo, termo sob o qual, segundo Choay (1988), abrigavam-se inicialmente o conjunto das praticas urbanísticas - ou seja, a efetivação de ações visando a resolução de problemas identificados na empiría da cidade.

O avanço da economia de mercado estimulou a consolidação do fenômeno cidade. Nestas cidades marcadas, conforme Simmel, pela intensificação dos estímulos sociais, experimentou- se também a intensificação dos estímulos sensíveis. Cheiros,

\footnotetext{
${ }^{7}$ Esta aproximação teve inicio com o ingresso no mestrado acadêmico em Planejamento Urbano e Regional, PRPUR/UFRGS, no ano de 2008.
} 
visuais, texturas, sons tornaram-se quantitativamente variados, intensos. Neste mesmo momento novas formas de pensar permitiram a problematização de temas antes inexplorados como a sociedade e mesmo o crescente fenômeno cidade (Elias, 2006).

O processo de transformação da intervenção no espaço como prática destituída de reflexão científica para a concepção de intervenção regida por leis e marcada pela reflexividade foi impulsionado pela experiência de cidade pós Revolução Industrial. A Revolução Industrial, marcada pelo desenvolvimento de técnicas, tecnologias e do mercado financeiro, demandou o aumento da oferta de força de trabalho. Tal fato implicou no aumento drástico do numero de habitantes nas cidades industriais. $\mathrm{Na}$ cidade industrial, as insalubres condições de moradia, trabalho, saneamento e, de maneira geral, de vida, são o ponto de partida para a problematização das formas de cidade existente e para a proposição de outras maneiras de organizar o espaço.

$\mathrm{O}$ estudo do fenômeno cidade dialogou com o desenvolvimento do conhecimento cientifico da época. Tal diálogo de certa forma determinou alguns aspectos do nascente urbanismo como ciência. Assim, pode-se dizer que o recorte ao fenômeno cidade realizado pelos primeiros urbanistas era ao mesmo tempo fruto e gerador de uma concepção de ciência da época onde a função normativa instaurava-se como fator legitimador da ciência. O caráter normativo das ciências, e em especial, do nascente urbanismo, influenciou os aspectos que foram salientados e os que foram suprimidos no estudo da cidade. Pois, é a partir da experiência de cidade pós Revolução industrial marcada pela precariedade, que a cidade passa a ser objeto de reflexão como forma de buscar leis e princípios orientadores das intervenções nas cidades.

Enquanto o urbanismo remete a tradições lingüísticas latinas, o planejamento urbano e regional origina-se da raiz lingüística anglo-saxônica. A tradução para o português da bibliografia inaugural desta área do conhecimento, redigida em francês, inglês, alemão e espanhol, atuou na instauração de uma variedade de significantes para uma mesma prática. Outro fator influente na apropriação pela academia brasileira das duas noções reside na formação de acadêmicos brasileiros em países ${ }^{8}$ estrangeiros.

\footnotetext{
${ }^{8}$ Neste sentido, cabe observar que o primeiro programa de pós-graduação em planejamento urbano e regional brasileiro foi fundado em 1970, e, por este motivo, até esta data todos os títulos de pósgraduação de pesquisadores brasileiros haviam sido obtidos no exterior. Principalmente na França, Inglaterra e Estados Unidos.
} 
Uma séria dificuldade que se apresenta para a construção da história do planejamento urbano no Brasil é que nele, comumente, discurso e prática se mesclam de tal forma que é difícil separá-los. (Villaça, 2001: 173).

O Planejamento Urbano e Regional designa no Brasil simultaneamente um discurso, uma prática e, acrescenta-se, uma área do conhecimento. A prática do planejamento urbano e regional diz sobre intervenções estatais no planejamento urbano - englobando aspectos físicos, sociais e econômicos. Remetendo aos planos diretores, a regulação fundiária... Já a área do conhecimento Planejamento Urbano e Regional, uma Ciência Social Aplicada, dirige-se à produção de conhecimento para embasar processos de planejamento urbano e regional; ao estudo dos processos empíricos de planejamento urbano, sua história, suas regularidades; e, dentre outro, à proposição de modelos de sintaxe e estrutura urbana.

Junta-se ao conteúdo do nó planejamento urbano e regional/urbanismo a disputa pela atuação em cada uma das áreas.

Em países com uma larga tradição e uma cultura de planejamento consolidada, o planejamenro urbano é, de fato, um campo que congrega os mais diferentes profissionais.(...) No Brasil, porém, ainda é comum as pessoas imaginarem que planejadores urbanos são sempre arquitetos. (Souza, 2002: 55-56).

Apresentado este quadro mais geral do que identifica-se como planejamento urbano e regional no Brasil, e tendo em vista que este estudo tem como objeto empírico os estudos sobre os sons da cidade da área planejamento urbano e regional brasileira, pontua-se que para abranger tal empiria está sendo proposta delimitação do campo de estudos planejamento urbano regional a partir de temáticas de pesquisa.

\section{Os sons ouvidos pelos estudos em Planejamento Urbano e Regional}

Até o presente momento foi possível verificar que na literatura acadêmica da área PUR os sons da cidade são tema de baixa recorrência e, que, dentre os estudos realizados com produtos publicados, identifica-se tendência em tratar o som como um problema, como ruído, como causador de poluição sonora, como fator prejudicial à saúde.

Sobre a relação entre a experiência social cotidiana e a forma como os sons vieram a ser tratados pelos estudos das áreas do conhecimento planejamento urbano e regional e urbanismo destaca-se que no urbanismo moderno os sons não foram aspecto da cidade de destaque. Provavelmente tal fato guarde relação com o 
desenvolvimento da atitude blasé. Pois, se era tão intensificada a massa sonora da experiência cotidiana da cidade industrial se comparada com a experiência de cidade anterior a Revolução Industrial, pode-se inferir que o desenvolvimento de barreiras a percepção racional de sons influenciou o tratamento destes pela ciência. Ou seja, propõe-se que a performatização da atitude blasé pelos cientistas, pelos urbanistas, nas suas vidas cotidianas em relação aos sons como estratégia para tornar viável as suas experiências cotidianas teve como conseqüência no plano da ciência a mesma atitude para com os sons. Assim foi, no momento de formação do urbanismo moderno, a relação dos urbanistas com o som e de certa forma pode-se dizer que ainda o é. Uma vez que, nas publicações atuais ainda nota-se uma baixa ocorrência de estudos sobre os sons mesmo que da inexistência do fenômeno cidade e da vivencia deste deslocada de componente sonoro. E ainda, nas publicações contemporâneas que tratam dos sons, estes aparecem como problema, evidenciando que, os sons, quando percebidos, o são por ultrapassar a barreira sociopsicológiga estabelecida pela atitude blasé. Assim ratifica-se que sons não são tema de grande recorrência nas publicações das áreas do conhecimento planejamento urbano e regional e urbanismo não por não serem importantes para a compreensão do fenômeno cidade e proposição de intervenções sobre este, mas por que os sons, como aspectos integrantes do componente sensível da cidade e da sua experiência são cotidianamente percebidos através do filtro que é a atitude blasé. Que é um recurso, uma estratégia, para tornar possível a vida na grande cidade, no sentido que para poder experenciar com profundidade alguma troca social, é necessário deixar de lado, ignorar, uma série de outras trocas que se apresentam disponíveis.

\section{Apontamentos}

A cidade contemporânea e as relações que nela têm lugar são tema de amplo interesse acadêmico, sendo focadas por diversas áreas do conhecimento - são exemplos pesquisas realizadas no campo sociológico, antropológico, geográfico, urbanístico e arquitetônico. No entanto, frente à identificação de que aspectos referentes à experiência sensível da vida urbana não costumam ser privilegiados nos estudos da área PUR, buscou-se discutir possibilidades de pensar a cidade desde as sonoridades que a constituem.

A partir pesquisa exploratória em veículos de divulgação científica dos estudos em Planejamento Urbano e Regional constatou-se, dentre os trabalhos que tratam de 
aspectos sensíveis da experiência urbana, tendência em privilegiar aspectos visuais frente às outros aspectos sensíveis como no caso dos sons e cheiros. Os elementos não-visuais do ambiente urbano tendem a ser resgatados apenas desde seus aspectos negativos ou negativados - este é o caso de alguns estudos preocupados com a poluição sonora, e os níveis de ruído prejudiciais à saúde. No entanto, do domínio da vida cotidiana os sons da cidade apresentam-se como elementos onipresentes e integrantes dos processos individuais de atribuição de sentido à experiência urbana cotidiana. Permitindo, desta maneira, a seguinte formulação: de que para os processos de regulação dos sons da cidade, a compreensão dos sons para além da sua atuação como ruído é importante para a proposição de legislação que contemple outras facetas deste fenômeno, dialogando desta forma com os sentidos atribuídos aos sons pelos indivíduos que produzem o espaço em questão.

Reconhecendo a participação do som na vida cotidiana não apenas como efeitos da mesma, mas como constituintes desta enquanto experiência sensível. Pode-se dizer que os sons da cidade encerram em si a capacidade de produzir interferências sobre a maneira como a cidade é vivida pelos indivíduos cotidianamente, sobre a maneira como as relações sociais são realizadas. E, estas interferências, manifestarem-se através da produção de sentidos na forma de problemáticas e negativações, na produção de sentidos como algo positivo e aprazível, ou ainda sem atribuição de juízos de valor.

Quanto à constatação de que sons não se constituem como tema de destaque no estudo da cidade e que, quando tratados costumam o ser como negatividades, como ruído gerador de interferências, perturbações, sugere-se que a capacidade dos indivíduos de agir seletivamente em relação aos sons na vida cotidiana atua na prática cientifica. Conduzindo desta forma à abordagem parcial dos sons - deixando de lado, por exemplo, o entendimento destes como elementos estimuladores, produtores de subjetividades - apresentando-se assim, como forma de obstáculo epistemológico.

Partindo da escuta da variedade de sons projetados nas diversas situações e indagando sobre a atuação destes sons no cotidiano na cidade propões-se o entendimento de que os sons e a escuta são aspectos relevantes dos processos de reconhecimento do espaço da cidade. E ainda, mesmo sendo a escuta e - de certa maneira, o ato de atribuição de sentidos - atividades efetivadas individualmente, elas remetem às sociabilidades urbanas e aos processos de estabelecimento e reestabelecimento destas. 
Quando os sons da cidade são ouvidos pelas pessoas, outras experiências sensíveis estão sendo simultaneamente vivenciadas. No entanto, a audição é definida como um sentido que permite a apreciação de um tipo de estímulo específico, que são as ondas sonoras. Logo, a percepção da onda sonora constitui-se como uma forma sui generis de fruir o mundo, a qual podem associar-se outros componentes sensíveis por exemplo, visuais ou olfativos. No entanto, reitera-se que mesmo frente à possibilidade de sinestesia, cada um dos sentidos apresenta-se um percurso que conduz à apreensão de diferentes aspectos do espaço urbano. Ainda neste sentido, pode-se dizer que assim como o que é visual se captura com o olhar, o que é sonoro se captura com a escuta.

A delimitação da audição como sentido marcado pela performatização da atitude blasé (que conduz por um lado à escuta de alguns sons da cidade e por outro, à não-escuta de um conjunto de outros sons) é proposta como contribuição para a compreensão das relações entre sons-cidade-cotidiano.

O estudo da cidade através dos sons passa a ser plausível uma vez reconhecido que parte da experiência cotidiana da cidade é sonora. Desta maneira, seria possível tanto o estudo dos espaços através do conhecimento de como as pessoas escutam um lugar, quanto o estudo de um espaço e das práticas efetivadas neste a partir da escuta deste mesmo espaço pelo pesquisador. Tendo em vista que o procedimento para conhecer a cidade a partir de seus sons implica na delimitação de metodologia para escuta ou para o estudo da escuta de um lugar, a continuidade deste trabalho aponta para reflexão sobre a documentação, registro e apresentação do conhecimento construído através estudo com sons.

\section{Referências}

CERTEAU, Michel de. A invenção do cotidiano: vol.1 - artes de fazer. Petrópolis, RJ: Editora Vozes, 1994, p. 169-217.

CHOAY, Françoise. Urbanisme. In: Pierre MERLIN, Françoise CHOAY (ed.). Dictionnaire de l'urbanisme et de l'aménagement. Paris: PUF, 1988, pp. 683-690. (Tradução de João Farias Rovati)

ELIAS, Norbert. Sobre a sociogênese da economia e da sociologia. In: Escritos e ensaios: estado, processo, opinião pública. Rio de Janeiro: Jorge Zahar Ed., 2006. MARTIN, Peter J. Sounds and Society: Themes in the sociology of music. New York: Manchester University Press, 1995.

SCHAFER, R. Murray. A afinação do mundo. São Paulo: Fundação Editora da Unesp 2001.

SIMMEL, Georg. A metrópole e a vida mental. In: O fenômeno urbano. Guilherme Otavio Velho (org). Rio de Janeiro: Zahar, 1967. 
SOUZA, Marcelo Lopes. Mudar a Cidade: uma introdução crítica ao planejamento e à gestão urbanos. Rio de Janeiro: Bertrand Brasil, 2002.

VILLAÇA, Flávio. Espaço Intra-urbano no Brasil. São Paulo: Studio Nobel, 2001.

WISNIK, José Miguel. O som e o Sentido: uma outra história das músicas. São Paulo: Companhia das Letras, 2006. 